\title{
IMPLEMENTASI BACKPROPAGATION NEURAL NETWORK DALAM PRAKIRAAN CUACA DI DAERAH BALI SELATAN
}

\author{
I Made Dwi Udayana Putra ${ }^{1 \S}$, G. K. Gandhiadi ${ }^{2}$, Luh Putu Ida Harini ${ }^{3}$ \\ ${ }^{1}$ Jurusan Matematika FMIPA Universitas Udayana [dwiudayana@gmail.com] \\ ${ }^{2}$ Jurusan Matematika FMIPA Universitas Udayana [gandhiadigk@yahoo.com] \\ ${ }^{3}$ Jurusan Matematika FMIPA Universitas Udayana [ballidah@gmail.com] \\ ${ }^{\S}$ Corresponding Author
}

\begin{abstract}
Weather information has an important role in human life in various fields, such as agriculture, marine, and aviation. The accurate weather forecasts are needed in order to improve the performance of various fields. In this study, use artificial neural network method with backpropagation learning algorithm to create a model of weather forecasting in the area of South Bali. The aim of this study is to determine the effect of the number of neurons in the hidden layer and to determine the level of accuracy of the method of artificial neural network with backpropagation learning algorithm in weather forecast models. Weather forecast models in this study use input of the factors that influence the weather, namely air temperature, dew point, wind speed, visibility, and barometric pressure.The results of testing the network with a different number of neurons in the hidden layer of artificial neural network method with backpropagation learning algorithms show that the increase in the number of neurons in the hidden layer is not directly proportional to the value of the accuracy of the weather forecasts, the increase in the number of neurons in the hidden layer does not necessarily increase or decrease value accuracy of weather forecasts we obtain the best accuracy rate of $51.6129 \%$ on a network model with three neurons in the hidden layer.
\end{abstract}

Keywords : Artificial neural network method, Back propagation algorithm, Weather forecasting

\section{PENDAHULUAN}

Cuaca mempunyai peranan penting bagi kehidupan manusia dalam menjalani aktivitas terutama aktivitas di tempat terbuka. Informasi cuaca sangat bermanfaat bagi berbagai bidang, antara lain bidang pertanian, kelautan, dan penerbangan. Bidang pertanian membutuhkan informasi cuaca agar dapat menentukan pola musim tanam pertanian, informasi cuaca dalam bidang kelautan bermanfaat untuk menentukan waktu berlayar yang tepat bagi nelayan untuk mencari ikan di laut, dan informasi cuaca dalam bidang penerbangan bermanfaat untuk mencegah terjadinya kecelakaan pesawat yang diakibatkan oleh faktor cuaca.

Prakiraan cuaca yang akurat sangat dibutuhkan agar dapat meningkatkan kinerja dari bidang-bidang tersebut. Salah satu metode yang dapat digunakan dalam membuat prakiraan cuaca adalah jaringan syaraf tiruan karena metode jaringan syaraf tiruan dapat memberikan klasifikasi dari suatu cuaca (Ernawati, 2009).

Jaringan syaraf tiruan merupakan salah satu bagian dari metode kecerdasan buatan, dimana metode ini merepresentasikan cara kerja otak manusia untuk menyelesaikan suatu masalah klasifikasi (Hermawan, 2006). Salah satu algoritma dari jaringan syaraf tiruan yang dapat digunakan dalam menyelesaikan masalah klasifikasi adalah algoritma back-propagation.

Backpropagation merupakan algoritma yang menggunakan metode pembelajaran yang terawasi dan termasuk jaringan dengan banyak lapisan. Pada jaringan backpropagation terdapat tiga lapisan, yaitu lapisan input, lapisan tersembunyi, dan lapisan output. Setiap lapisan 
dari jaringan memiliki satu atau lebih neuron (Hermawan, 2006).

Lapisan input terdiri dari neuron-neuron yang merupakan input dari jaringan berupa faktor-faktor yang memengaruhi cuaca yaitu suhu udara, titik embun, kecepatan angin, jarak pandang, dan tekanan udara. Lapisan output merupakan solusi dari jaringan di mana neuron dari lapisan output berisikan output dari jaringan yaitu hasil prakiraan cuaca. Jumlah neuron pada lapisan input tergantung pada banyaknya input dari jaringan dan jumlah neuron pada lapisan output juga tergantung pada banyaknya output dari jaringan, akan tetapi untuk jumlah neuron pada lapisan tersembunyi tidak dapat ditentukan secara langsung sehingga perlu dilakukan analisis untuk menentukan jumlah neuron pada lapisan tersembunyi.

Penelitian terkait jaringan syaraf tiruan dengan algoritma pembelajaran backpropagation dilakukan oleh Priyanta untuk memprakirakan hujan harian di daerah Kuta Selatan Bali. Pada penelitian tersebut, output yang dihasilkan hanya dua kejadian, yaitu hujan dan tidak hujan (Priyanta, 2014).

Pada penelitian ini digunakan metode jaringan syaraf tiruan dengan algoritma pembelajaran backpropagation untuk memprakirakan cuaca di daerah Bali Selatan dengan output 15 kejadian cuaca yaitu cerah, cerah berawan, cerah berawan dengan awan cumulonimbus $(\mathrm{CB})$, berawan, berawan dengan awan cumulonimbus (CB), badai guntur, hujan ringan, hujan ringan dengan awan cumulonimbus (CB), hujan sedang, hujan sedang dengan awan cumulonimbus (CB), hujan lebat, hujan lebat dengan awan cumulonimbus (CB), hujan ringan dengan badai guntur, hujan sedang dengan badai guntur dan hujan lebat dengan badai guntur.

Informasi cuaca dengan awan cumulonimbus (CB) sangat ditekankan pada penelitian ini karena awan cumulonimbus (CB) ini sangat berbahaya dalam suatu penerbangan, mengingat banyak kecelakaan pesawat yang diakibatkan oleh awan cumulonimbus (CB).

\section{BACKPROPAGATION}

Backpropagation adalah salah satu algoritma pada jaringan syaraf tiruan yang sering digunakan dalam mencari bobot optimal. Pada jaringan backpropagation terdapat pola input dan pola output yang diinginkan. Pada saat jaringan diberikan suatu pola, nilai bobotbobot diubah agar dapat memperkecil perbedaan antara pola output dari jaringan dan pola output yang diinginkan. Pelatihan jaringan dilakukan berulang-ulang sampai semua pola output dari jaringan dapat mengenali pola output yang diinginkan (Hermawan, 2006).

\subsection{Inisialisasi Bobot Awal}

Inisialisasi bobot awal dari algoritma ini diperoleh dari proses acak atau dngan menggunakan algoritma Nguyen-Widrow. Algoritma Nguyen-Widrow merupakan algoritma optimasi nilai bobot dan bias awal dari jaringan backpropagation sehingga proses belajar jaringan untuk mencapai bobot optimal menjadi lebih cepat dibandingkan dengan pengini-sialisasian secara random/acak.

Algortima inisialisasi Nguyen-Widrow adalah (Fausett, 1994):

1. Tentukan:

$n=$ jumlah neuron input

$p=$ jumlah neuron pada lapisan tersembunyi

$\beta=$ faktor skala dengan nilai $0,7 \sqrt[n]{p}$

2. Inisialisasi bobot-bobot $\left(v_{i j}\right.$ (lama) menggunakan nilai acak antara $-0,5$ dan 0,5 .

3. Hitung $\left\|v_{i j}\right\|=\sqrt{v_{1 j}^{2}+v_{2 j}^{2}+\ldots+v_{n j}^{2}}$

4. Bobot yang dipakai sebagai inisialisasi $v_{i j}=\frac{\beta v_{i j}(\text { lama })}{\left\|v_{i j}\right\|}$

Nilai bias yang digunakan, $v_{0 j}=$ bilangan acak antara $-\beta$ dan $\beta$.

\subsection{Fungsi Aktivasi}

Fungsi aktivasi yang digunakan dalam backpropagation harus memenuhi tiga syarat, yaitu kontinu, terdeferensial dengan mudah, dan merupakan fungsi tidak turun (Fausett, 1994). 
Fungsi aktivasi yang paling sering digunakan dalam jaringan syaraf tiruan adalah fungsi sigmoid biner dan didefinisikan sebagai berikut.

$$
f(x)=\frac{1}{1+e^{-x}}
$$

dan turunannya

$$
f^{\prime}(x)=f(x)(1-f(x))
$$

Fungsi sigmoid biner mempunyai nilai maksimum satu. Sehingga untuk pola input dan output dengan nilai lebih besar dari satu harus ditransformasi agar setiap polanya memiliki range nilai yang sama dengan fungsi sigmoid biner.

\subsection{Algoritma Pelatihan Backpropagation}

Berikut adalah algoritma pelatihan backpropagation (Hermawan, 2006):

(1) Inisialisasi bobot awal dengan bilangan acak kecil.

(2) Tentukan maksimum iterasi, Target error yang diinginkan, dan Learning rate $(\alpha)$.

(3) Bila kondisi berhenti bernilai FALSE, kerjakan langkah-langkah berikut:

1. Untuk setiap pasangan elemen pelatihan, kerjakan:

Feedforward:

a. Setiap neuron input $x_{i}$ dengan $i=1,2,3, \ldots, n$, mendapat sinyal $x_{i}$ dan diteruskan ke semua neuron pada lapisan tersembunyi.

b. Setiap neuron pada suatu lapisan tersembunyi $z_{j}$ dengan $j=1,2,3, \ldots, p$, menjumlahkan sinyal-sinyal input berbobot:

$$
z_{-} n e t_{j}=v_{0 j}+\sum_{i=1}^{n} x_{i} v_{i j}
$$

dengan menerapkan fungsi aktivasi, hitung sinyal output pada lapisan tersembunyi:

$$
z_{j}=f\left(z_{-} n e t_{j}\right)
$$

selanjutnya kirimkan sinyal tersebut ke semua neuron di lapisan output. c. Setiap neuron output $y_{k}$ dengan $k=1,2,3, \ldots, m$, menjumlahkan sinyalsinyal input berbobot:

$$
y_{-} n e t_{k}=w_{0 k}+\sum_{j=1}^{p} z_{j} w_{j k}
$$

dengan menerapkan fungsi aktivasi, hitung sinyal output pada lapisan output:

$$
y_{k}=f\left(y_{\_} n e t_{k}\right)
$$

Catatan: langkah (b) dilakukan sebanyak jumlah lapisan tersembunyi.

Backpropagation:

d. Setiap neuron output $y_{k}$ dengan $k=1,2,3, \ldots, m$, menerima target pola output yang berkaitan dengan pola input pelatihan. Hitung error pada lapisan output:

$$
\delta_{k}=\left(t_{k}-y_{k}\right) f^{\prime}\left(y_{-} n e t_{k}\right)
$$

$t_{k}$ adalah target output yang diharapkan.

Selanjutnya hitung perubahan bobot (digunakan untuk memperbaiki nilai bobot $w_{j k}$ ):

$$
\Delta w_{j k}=\alpha \delta_{k} z_{j}
$$

Hitung juga perubahan bobot bias (digunakan untuk memperbaiki nilai bobot $w_{0 k}$ ):

$$
\Delta w_{0 k}=\alpha \delta_{k}
$$

Kirimkan $\delta_{k}$ ini ke neuron pada lapisan tersembunyi.

e. Setiap neuron pada lapisan tersembunyi $z_{j} \quad$ dengan $j=1,2,3, \ldots, p$, menjumlahkan faktor delta pada lapisan tersembunyi :

$$
\delta_{-}{ }_{n} t_{j}=\sum_{k=1}^{m} \delta_{k} w_{j k}
$$

nilai ini dikalikan dengan turunan dari fungsi aktivasinya dan digunakan untuk menghitung informasi error pada lapisan tersembunyi:

$$
\delta_{j}=\delta_{-} n e t_{j} f^{\prime}\left(z_{-} n e t_{j}\right)
$$


selanjutnya hitung perubahan bobot (digunakan untuk memper-baiki nilai bobot $v_{i j}$ )

$$
\Delta v_{i j}=\alpha \delta_{j} x_{i}
$$

Selanjutnya hitung perubahan bobot bias (digunakan untuk memperbaiki nilai bobot $v_{0 j}$ ):

$$
\Delta v_{0 j}=\alpha \delta_{j}
$$

Perubahan bobot

f. Setiap neuron output $y_{k}$ dengan $k=1,2,3, \ldots, m$, memperbaharui bobot dan biasnya $(j=0,1,2, \ldots, p)$ : $w_{j k} *=w_{j k}+\Delta w_{j k}$ setiap neuron pada lapisan tersembunyi $z_{j}$ dengan, memper-baharui bobot dan biasnya $(i=0,1,2, \ldots, n)$ : $v_{i j} *=v_{i j}+\Delta v_{i j}$

\section{Tes kondisi berhenti}

Kondisi penghentian yang digunakan dalam algoritma ini adalah jumlah maksimum iterasi dan target error. Pelatihan akan dihentikan apabila jumlah iterasi pelatihan melebihi jumlah iterasi maksimum atau jika error yang diperoleh dalam pelatihan lebih kecil dari target error.

Pada tahap perubahan bobot dapat dimodifikasi dengan menambahkan momentum $(\mu)$ agar lebih cepat mencapai kekonvergenan.

Kecepatan kovergensi juga dapat ditingkatkan dengan memodifikasi learning rate menjadi adaptive dimana learning rate akan berubah-ubah selama proses pelatihan. Jika selisih antara error yang diperoleh dan error sebelumnya melebihi nilai maksimum kenaikan kinerja maka nilai bobot-bobot yang baru diabaikan, dan nilai leraning rate diturunkan dengan cara mengalikan dengan nilai penurunan leraning rate. Sebaliknya jika selisih error yang diperoleh dan error sebelumnya kurang dari maksimum kenaikan kinerja, semua nilai bobot yang baru akan disimpan, dan nilai learning rate ditingkatkan dengan cara mengalikan dengan nilai kenaikan learning rate (Hermawan, 2006).
Setelah pelatihan, dilakukan pengujian jaringan backpropagation dengan hanya menggunakan tahap feedforward dengan menggunakan bobot yang diperoleh dari proses pelatihan.

\subsection{Pengukuran Ketepatan Model Prakiraan}

Mengukur ketepatan model prakiraan dapat dihitung dengan persamaan berikut (Whidhiasih, Guritman, \& Suprio, 2012): akurasi $=\frac{\text { total prakiraan y ang benar }}{\text { total prakiraan }} \times 100 \%$

\section{METODE PENELITIAN}

Penelitian ini menggunakan data sekunder, yang didapat dari website ogimet.com. Data yang digunakan dalam penelitian ini yaitu kecepatan angin (knot), jarak pandang (meter), suhu udara $\left({ }^{\circ} \mathrm{C}\right)$, titik embun $\left({ }^{\circ} \mathrm{C}\right)$, tekanan udara (milibar) dan cuaca di daerah Bali Selatan.

Data pada penelitian ini dibagi menjadi dua, yaitu data pelatihan yang ditetapkan dari 1 Desember 2013 sampai 31 Januari 2014 dan data pengujian yang ditetapkan dari 1 Desember 2014 sampai 31 Januari 2015. Pemilihan periode data pada bulan-bulan tersebut dikarenakan pada bulan-bulan tersebut cuaca yang terjadi cukup bervariatif.

Pada penelitian ini teknik analisis data yang digunakan adalah sebagai berikut:

1. Menentukan banyaknya neuron pada lapisan input. Banyaknya neuron yang digunakan pada lapisan input adalah lima buah neuron karena jumlah input yang digunakan sebanyak lima buah input berupa faktor yang memengaruhi cuaca yaitu suhu udara, titik embun, kecepatan angin, tekanan udara, dan jarak pandang.

2. Menganalisis banyaknya neuron pada lapisan tersembunyi. Jumlah neuron pada lapisan tersembunyi harus kurang dari dua kali jumlah neuron pada lapisan input (Yohannes \& Mahmudy, 2015). Jumlah neuron pada lapisan input adalah lima buah, sehingga dua kali jumlah neuron pada lapisan input adalah 10. Oleh karena itu jumlah neuron pada lapisan tersembunyi harus kurang dari 10 buah neuron. Pada 
penelitian ini jumlah neuron pada lapisan tersembunyi akan dianalisis dari satu buah neuron hingga 10 buah neuron.

3. Menentukan jumlah neuron pada lapisan output. Output yang dihasilkan adalah 15 kejadian cuaca yaitu cuaca cerah, cerah berawan, cerah berawan dengan awan cumulonimbus (CB), berawan, berawan dengan awan cumulonimbus (CB), badai guntur, hujan ringan, hujan ringan dengan awan cumulonimbus (CB), hujan sedang, hujan sedang dengan awan cumulonimbus (CB), hujan lebat, hujan lebat dengan awan cumulonimbus (CB), hujan ringan dengan badai guntur, hujan sedang dengan badai guntur dan hujan lebat dengan badai guntur. Output akan dibuat dalam empat buah neuron. Empat buah neuron pada lapisan output masing-masing akan berisikan satu digit bilangan biner sehingga akan ada empat digit bilangan biner, dimana kombinasi empat digit bilangan biner akan menghasilkan 16 kombinasi bilangan biner. Oleh karena itu, 15 kejadian cuaca akan dibuat ke dalam empat buah neuron.

4. Inisialisasi bobot dan bias awal menggunakan algoritma Nguyen-Widrow.

5. Melakukan pelatihan jaringan terhadap datadata pelatihan.

6. Melakukan pengujian jaringan dengan menggunakan data-data pengujian. Proses pengujian jaringan hanya menggunakan tahap feed-forward dan menggunakan bobotbobot yang diperoleh dari proses pelatihan.

7. Validasi model prakiraan cuaca. Tahap ini dilakukan untuk mengetahui persentase ketepatan model prakiraan cuaca.

\section{HASIL DAN PEMBAHASAN}

\subsection{Prakiraan Cuaca dengan Metode Jaringan Syaraf Tiruan}

Penerapan metode jaringan syaraf tiruan dengan algoritma pembelajaran backpropagation pada data cuaca di daerah Bali Selatan menggunakan fungsi aktivasi sigmoid biner.

\subsection{Transformasi Data}

Fungsi aktivasi sigmoid biner memiliki nilai maksimum satu, pada penelitian ini mengunakan data dengan nilai lebih dari satu, maka data harus ditransformasi ke selang [0,1 $0,9]$ terlebih dahulu agar data tersebut memiliki range yang sama dengan range nilai dari fungsi sigmoid biner.

\subsection{Pola Output}

Output atau target yang diinginkan pada penelitian ini berupa cuaca di daerah Bali Selatan dan terbagi dalam 15 pola. lima belas pola output di buat dalam empat buah neuron pada lapisan output. Empat buah neuron pada lapisan output berisikan empat digit bilangan biner dimana masing-masing neuron berisikan satu digit bilangan biner. Pola dari output atau target yang diinginkan dapat dilihat pada Tabel 1.

Tabel 1 Pola output atau target

\begin{tabular}{|l|l|l|}
\hline No & Cuaca & $\begin{array}{l}\text { Pola } \\
\text { Output }\end{array}$ \\
\hline 1 & Cerah & 0000 \\
\hline 2 & Cerah Berawan & 0001 \\
\hline 3 & Berawan & 0010 \\
\hline 4 & Cerah Berawan dg Awan CB & 0011 \\
\hline 5 & Berawan dg Awan CB & 0100 \\
\hline 6 & Badai Guntur & 0101 \\
\hline 7 & Hujan Ringan & 0110 \\
\hline 8 & Hujan Sedang & 0111 \\
\hline 9 & Hujan Ringan dg Awan CB & 1000 \\
\hline 10 & Hujan Sedang dg Awan CB & 1001 \\
\hline 11 & Hujan Ringan dg Badai Guntur & 1010 \\
\hline 12 & Hujan Sedang dg Badai Guntur & 1011 \\
\hline 13 & Hujan Lebat & 1100 \\
\hline 14 & Hujan Lebat dg Awan CB & 1101 \\
\hline 15 & Hujan Lebat dg Badai Guntur & 1110 \\
\hline
\end{tabular}

\subsection{Pelatihan Jaringan}

Tahap pelatihan jaringan merupakan proses pembelajaran terhadap pola data yang akan dikenali. Tahap pelatihan jaringan dilakukan dalam beberapa tahap, antara lain dengan inisialisasi bobot dan bias awal menggunakan algoritma Nguyen-Widrow, kemudian dilatih dengan algoritma pembelajaran backpropagation. 
Tahap pelatihan jaringan menggunakan algoritma pembelajaran backpropagation dengan momentum dan adaptive learning rate. Pelatihan jaringan dilakukan menggunakan Matlab 7.8.0 (R2009a).

Proses pelatihan dilakukan menggunakan data-data pelatihan dengan target error ditentukan sebesar 0,01 ; untuk nilai learning rate ditentukan sebesar 0,1 ; untuk nilai momentum ditentukan sebesar 0,9 dan maksimum iterasi ditentukan 1.000.000 iterasi. Pada proses pelatihan, nilai learning rate bersifat adaptive yang berubah-ubah selama proses pelatihan. Jika selisih antara error yang diperoleh dan error sebelumnya melebihi nilai maksimum kenaikan kinerja maka nilai bobotbobot yang baru diabaikan, dan nilai leraning rate diturunkan dengan cara mengalikan dengan nilai penurunan leraning rate dimana nilai penurunan lerning rate yang ditentukan sebesar 0,7. Sebaliknya jika selisih error yang diperoleh dan error sebelumnya kurang dari mak-simum kenaikan kinerja, semua nilai bobot yang baru akan disimpan, dan nilai learning rate ditingkatkan dengan cara mengalikan dengan nilai kenaikan learning rate dimana nilai kenaikan lerning rate yang ditentukan sebesar 1,05. Nilai maksimum kenaikan kinerja ditentukan sebesar 1,04.

Proses pelatihan jaringan akan berhenti apabila jumlah iterasi telah melebihi batas maksimum yang ditentukan yaitu 1.000.000 iterasi, atau pelatihan akan dihentikan jika target error yang ditentukan telah tercapai.

Tahap pelatihan jaringan akan menghasilkan nilai bobot dan bias yang akan digunakan pada tahap pengujian jaringan.

\subsection{Pengujian Jaringan}

Tahap pengujian jaringan digunakan untuk menguji validasi data yang telah dilakukan pada tahap pelatihan dengan memasukkan data baru yang belum pernah dilatih sebelumnya untuk mengetahui nilai akurasi yang dihasilkan. Data yang digunakan pada tahap pengujian jaringan ini adalah data pengujian. Tahap pengujian jaringan dilakukan dengan menggunakan nilai bobot dan bias yang diperoleh dari tahap pelatihan jaringan. Pada tahap pengujian jaringan ini hanya menggunakan tahap feedforward pada algoritma pembelajaran backpropagation. Hasil yang didapat pada tahap ini adalah output berupa prakiraan cuaca.

Setelah diperoleh hasil prakiraan cuaca, kemudian dihitung akurasi kete-patan kejadian cuaca yang sebenarnya dengan hasil prakiraan cuaca meng-gunakan jaringan syaraf tiruan dengan algoritma pembelajaran backpropagation.. Akurasi hasil prakiraan cuaca da-pat dilihat pada Tabel 2.

Tabel 2. Akurasi hasil prakiraan cuaca

\begin{tabular}{|l|l|c|c|l|}
\hline No & $\begin{array}{l}\text { Jumlah } \\
\text { Neuron } \\
\text { pada } \\
\text { Lapisan } \\
\text { Input }\end{array}$ & $\begin{array}{l}\text { Jumlah Neuron } \\
\text { pada Lapisan } \\
\text { Tersembunyi }\end{array}$ & $\begin{array}{l}\text { Jumlah } \\
\text { Neuron } \\
\text { pada } \\
\text { Lapisan } \\
\text { Output }\end{array}$ & $\begin{array}{l}\text { Akurasi } \\
(\%)\end{array}$ \\
\hline 1 & 5 & 1 & 4 & 45,1613 \\
\hline 2 & 5 & 2 & 4 & 39,5161 \\
\hline 3 & 5 & 3 & 4 & 51,6129 \\
\hline 4 & 5 & 4 & 4 & 45,9677 \\
\hline 5 & 5 & 5 & 4 & 44,3548 \\
\hline 6 & 5 & 6 & 4 & 34,6774 \\
\hline 7 & 5 & 7 & 4 & 41,9355 \\
\hline 8 & 5 & 8 & 4 & 40,7258 \\
\hline 9 & 5 & 9 & 4 & 40,3226 \\
\hline 10 & 5 & 10 & 4 & 46,7742 \\
\hline
\end{tabular}

Penambahan jumlah neuron pada lapisan tersembunyi tidak berbanding lurus dengan nilai akurasi hasil prakiraan cuaca. Nilai akurasi tertinggi terjadi pada model jaringan dengan tiga buah neuron pada lapisan tersembunyi dengan nilai akurasi sebesar 51,6129\% sedangkan nilai akurasi terendah diperoleh pada model jaringan dengan enam buah neuron pada lapisan tersembunyi dengan nilai akurasi sebesar $34,6774 \%$.

Model jaringan dengan satu buah neuron pada lapisan tersembunyi mendapatkan nilai akurasi sebesar 45,1613\%, namun terjadi penurunan nilai akurasi pada model jaringan dengan dua buah neuron pada lapisan tersembunyi yang mendapatkan nilai akurasi sebesar 39,5161\%. Pada model jaringan dengan tiga buah neuron mendapatkan nilai akurasi sebesar 51,6129\% dimana terjadi peningkatan 
nilai akurasi dari nilai akurasi model jaringan dengan dua buah neuron pada lapisan tersembunyi. Hal ini menandakan bertambahnya jumlah neuron pada lapisan tersembunyi tidak serta merta meningkatkan atau menurunkan nilai akurasi prakiraan cuaca yang diperoleh dengan metode jaringan syaraf tiruan dengan algoritma pembelajaran backpropagation.

\section{KESIMPULAN}

Berdasarkan hasil dan pembahasan, dapat dikesimpulkan sebagai berikut:

1. Penambahan jumlah neuron pada lapisan tersembunyi tidak berbanding lurus dengan nilai akurasi hasil prakiraan cuaca. Bertambahnya jumlah neuron pada lapisan tersembunyi tidak serta merta meningkatkan atau menurunkan nilai akurasi prakiraan cuaca yang diperoleh dengan metode jaringan syaraf tiruan dengan algoritma pembelajaran backpropagation.

2. Hasil prakiraan cuaca di daerah Bali Selatan menggunakan metode ja-ringan syaraf tiruan dengan algoritma pembelajaran backpropagation diperoleh tingkat akurasi prakiraan cuaca terbaik sebesar 51,6129\% pada model jaringan dengan tiga buah neuron pada lapisan tersembunyi.

\section{DAFTAR PUSTAKA}

Ernawati, S. (2009). Aplikasi Hopfield Neural Network untuk Prakiraan Cuaca. Meteorologi dan Geofisika, 151-175.

Fausett, L. (1994). Fundamentals of Neural Network. New York: Prentice Hall.

Hermawan, A. (2006). Jaringan Syaraf Tiruan Teori dan Aplikasi. Yogyakarta: ANDI.

Priyanta, I. B. (2014). Penerapan Algoritma Genetika pada Jaringan Syaraf Tiruan dalam Prakiraan Hujan Harian di Daerah Kuta Selatan Provinsi Bali. Skripsi. Program Studi Teknik Informatika Jurusan Ilmu Komputer Fakultas Matematika dan Ilmu Pengetahuan Alam, Universitas Udayana. Bukit Jimbaran.

Whidhiasih, R. N., Guritman, S., \& Suprio, P. T. (2012). Klasifikasi Kematangan Buah Manggis Ekspor dan Lokal Berdasarkan
Warna dan Tekstur Menggunakan Fuzzy Neural Network. JIKA, 71-77.

Yohannes, E., \& Mahmudy, W. F. (2015). Penentuan Upah Minimum Kota Berdasarkan Tingkat Inflasi Menggunakan Backpropagation Neural Network (BPNN). Jurnal Teknologi Informasi dan Ilmu Komputer (JTIIK), 33-40. 